\title{
Efficacy of Tricompost on Vegetative Growth of Chilli Plant
}

\section{Laila Naher* and Nornadillanadia Binti Abdul Rapar}

Faculty of Agro-based Industry, Department of Agriculture Science, Universiti Malaysia Kelantan, Kelantan, Malaysia

*Corresponding Author: Laila Naher, Faculty of Agro-based Industry, Department of Agriculture Science, Universiti Malaysia Kelantan, Malaysia.

Received: April 24, 2019; Published: June 11, 2019

DOI: 10.31080 /ASAG.2019.03.0518

\begin{abstract}
The objective of the study was to determine the efficacy of Tricompost as biofertilizer as maintenance for the chilli plant growth and productivity in the net house at Agropark, UMK jeli campus. The treatments were: T1 = $100 \mathrm{~g}$ Tricompost, T2 = $10 \mathrm{~g}$ chemical, $\mathrm{T} 3=$ control, $\mathrm{T} 4=50 \mathrm{~g}$ Tricompost $+5 \mathrm{~g}$ chemical, $\mathrm{T} 5=15 \mathrm{~g}$ chemical and $\mathrm{T} 6=150$ Tricompost. A total of 53 chilli seedlings were planted in polybags contained soils. Plant growth was determined based on plant length, diameter of stem and number of leaves. The result showed that T6 (150 Trichocompost $+15 \mathrm{~g}$ NPK) was effective for the highest growth of chili plant and increased the number of leaves while T5 (15 g NPK) result was highest in length of chili plant growth among the rest other treatments. To vast using chemical fertilizer can increase the yield; nevertheless, chemical residues caused environment pollution. The result of this study indicate that Trichocompost had the efficacy to growth chilli plant as like chemical fertilizer; thus it might be inform that combination of Trichocompost and chemical fertilizer can play role to reduce the unparalleled using of chemical fertilizer.
\end{abstract}

Keywords: Chilli Plant; Trichocompost; Bio Control Agent; Antagonistic Activity; Growth

\section{Introduction}

Nowadays, people are more interest in application of chemical fertilizer on their vegetables and fruits crops due to the ability of chemical fertilizer in increasing yield productivity. Chemical fertilizer paly to increase crop productivity, but they also bring an impact on human health. Excessive use of chemical nowadays created serious environmental problem [1].

Mismanagement of chemical fertilizer brings the side impact to environments such as pollution of rivers, lakes and stream flows. Common examples chemical fertilizer used in chilli plant by farmers in Malaysia are NPK 30-10-10 Hydroponic Fertilizer (solid) and B fertilizer (liquid) while example of biocompost in market today for chilli planting such Garden Boost Sheep Wool Sheep Wool Pallet (sheep manure pallet) [2]. A study by [3] Alfred (2007) had discussed the properties of chemical fertilizer which have the ability in harden the soil and reduce soil fertility. Moreover, leeching of chemical fertilizer to water stream and environment surrounding can caused water and air pollution.
Chemical fertilizer can depletes essential nutrient and minerals in soil. In fertile soil, nutrient are replenish but in chemical fertilizer application only replenish in nitrogen, phosphorus and potassium. Potassium are not soluble in water. Thus, it cause the hardened soil structure formation. Sodium nitrate the alkaline fertilizer can reduce the soil fertility and making it barren. Soil degradation due excessive use of chemical leads to the loss of equilibrium of a stable soil. Though the use of chemical fertilizer help in growing the plants faster, plant are not healthy and strong due to short time on the growth of root, stem and nutritious fruits.

In addition, chemical fertilizer contains heavy metal such as cadmium and chromium have high radionuclides concentration. Wide use of chemical fertilizer cause more serious in accumulation of inorganic pollutants. Amount of nitrite in drinking water. To overcome this problem, best way to use biofertilizer that can help to reduce the use of chemical fertilizer. With this regards, this study was aimed to use biocompost of Trichocompost on maintenance of chilli plant growth in net house experiment. 


\section{Materials and Methods}

Collection of samples

Sugarcane waste $(6 \mathrm{~kg}$ ) was collected from farmers in Kedah. Citrus leaves were purchased from Jeli market for 500 g (RM5). Antigonon leptopus leaves were collected from UMK Jeli Campus tunnel garden. Compost was decomposed by sing Trichoderma parareesei which was collected from the stock culture (Biology laboratory, UMK Jeli Campus).

\section{Pure Culture of Trichoderma parareesei}

The pure culture of Trichoderma parareesei was performed from the stock culture of Trichoderma parareesei which was isolated and identified in another study. Trichoderma parareesei from the stock culture was transferred on PDA (potato dextrose agar) containing plate of mycelia. The culture was carried in fume chamber to prevent the contamination. All the culture were sealed neatly by parafilm. The plate were incubated for full growth colony in the room temperature at $30^{\circ} \mathrm{C}$ for 7 - 8 days. The full growth of the culture of Trichoderma parareesei plates were kept for further study.

\section{Suspension Preparation of Trichoderma Parareesei}

Trichoderma parareesei was diluted with $10 \mathrm{ml}$ of treated distilled water to prepare Trichoderma parareesei suspension. The culture was mixed by using a glass rod. Suspension process was carried in fume chamber. All prepared suspension were kept in test tubes with closely tightly. They were used for Tricompost preparation.

Counting Spores of T: parareesei by Haemocytometer

A drop of Trichoderma parareesei suspension was poured on haemocytometer for counting the spore from cultures plate before applying in Trichocompost and then after 2 weeks growth in Trichocompost. The Trichoderma parareesei spores counted using the formula 1 as below:

Number of spores $=$ Number of spores $/ 25$ boxes $\times 25$ boxes $\times$ 1 / total volume $(10 \mathrm{ml})$

\section{Preparation of Trichocompost}

Sugarcane, leaves of Antigonon leptopus and citrus leaves were washed thoroughly with water and then the sample were dried under the hot sun for 4 days. All the samples were crushed into small size by miller. A total of $80 \mathrm{~g}$ of sugarcane, $10 \mathrm{~g}$ of rice husk and $5 \mathrm{~g}$ of dried leaves of Antigonon leptopus, $5 \mathrm{~g}$ of citrus leaves and 1 plate of Trichoderma parareesei suspension $(10 \mathrm{ml})$ was transferred in a pack of $100 \mathrm{~g}$ of Trichocompost. A total of 80 Trichocompost bags were prepared and kept in a closed box not near the light sources for microbial growth inside packs for 2 weeks.

\section{Soil Filing to polybags and tagging}

A total of 54 polybags were filled with sandy and loamy soil from Agropark, Universiti Malaysia Kelantan, Jeli Campus. They were been weighed to achieve $4 \mathrm{~kg}$ of soil for each polybags before transplanting the seedlings. Polybags of soil were arranged randomly in nursery.

\section{Plant treatments}

Trichocmpost were used to maintenance of the vegetative growth in chilli plant. A total of 54 seedlings of chilli on the age of 30 days were transferred from the trays to the polybag filled with $4 \mathrm{~kg}$ of soil. They were been watered every morning at 8.00a.m and evening 6.00p.m to keep the moisture for the seedlings growth condition. The reason to do the early watering on the chilli plant to prevent the extreme water loss on the high temperature during the day. Six different treatment were used on chilli plant to observe the effectiveness of Trichocompost which shown in Table 1.

\begin{tabular}{|c|c|c|}
\hline Treatment & Composition & $\begin{array}{c}\text { Total } \\
\text { Plant }\end{array}$ \\
\hline T1 & 100 g of Trichocompost & 9 \\
T2 & 10 g of Chemical Fertilizer, NPK & 9 \\
T3 & Control & 9 \\
T4 & 50 g of Trichocompost + 5 g of & 9 \\
T5 & Chemical Fertilizer & 9 \\
T6 & 150 g Trichocompost +15 g of NPK & 9 \\
\hline
\end{tabular}

Table 1: Layout of Treatments on Chilli Plant.

\section{Data Collection and analysis}

Growth of chilli plant were observed on the parameters of length, stem diameter, number of leaves, presence of branch. Data was collected on 6 weeks plant growth. All collected data were analyzed by ANOVA test to determine the significant differences among the treatments on maintenance of growth for chilli plant. 


\section{Results and Discussion}

\section{Counting Trichoderma parareesei spore}

A cultured plate of Trichoderma parareesei was diluted with $10 \mathrm{ml}$ of distilled water. Before Trichompost preparation the number of spore of $T$. parareesei was counted to observe the spore density. One drop of T. parareesei suspension was poured on haemocytometer and counted the spore under light microscope. The spore counting was analyzed using formula 1 . The analysed result showed that Trichoderma parareesei spores were $19 \times 10^{7}$ spores/ $\mathrm{ml}$. Then, a plate of T. parareesei was poured into a packet of Tricompost and mixed thoroughly. Same procedure was used in 2 weeks growth of Trichocompost to calculate the spore of $T$. parareesei in Trichocompost and it was $179 \times 10^{7}$ spores $/ \mathrm{ml}$. It is noted that the spore number increased of $T$. parareesei after been for 2 weeks in the compost. It showed that compost ingredients help for enhancing sporulation of T. parareesei spore. For spore sporulation in compost, the proper ingredient play a role as good media for enhancing spore sporulation. In study of Yang., et al. [4] showed that arbuscular mycorrhizal (AM) spores were increased in cow manure and maize straw combination compost.

Assessment of Trichocompost for vegetative growth of Chilli plant

In this study to observe the efficacy of Trichocompost for maintenance of chilli plant growth was conducted by assessment of plant highest, plant diameter, shoot growth and leaves number among the six treatments. The treatments were T1: $100 \mathrm{~g}$ Trichocompost; T2: 10 g NPK fertilizer; T3: control, without any treatments; T4: $50 \mathrm{~g}$ of Trichocompost $+5 \mathrm{~g}$ of Chemical Fertilizer; T5: 15 g NPK, and T6: 150 g Trichocompost +15 g of NPK. Plant growth length was highest at week 6 in Treatments of T2, T5 and T6. It also showed that However, T4 is the first highest among T2 and T5, it can be noted that nutrient uptake stimulate from NPK in the presence of good concentrate trichocompost in treatment 6. However, there was similar plant diameter growth observed in all treated plants whereas the number of leaves were different in each treatment. The highest number of leaves were observed in T2, T5 and T6 treatments. Here also noted that number of leaf increased of good concentrate trichocompost in treatment 6. A similar trend also observed in study of Tomato plant which was treated with Trichoderma enriched biofertilizer and NPK fertilizer combination, however, it showed that $50 \%$ of Trichoderma enriched biofertilizer either soild or liquied and 50\% NPK fertilizer produced the highest yield compare to control and Trichoderma enriched biofertilizer alone or NPK alone treated tomato plant [5]. Trichoderma is filamentous fungus well known for biocontrol agent, while it has extraordinary ability that enhanced plant growth. The secondary compounds in this group of fungus harzianolide, anthraquinoues, T39 butenolide isolated and evident showed incorporated with these compounds enhanced plant growth of wheat plant [6].

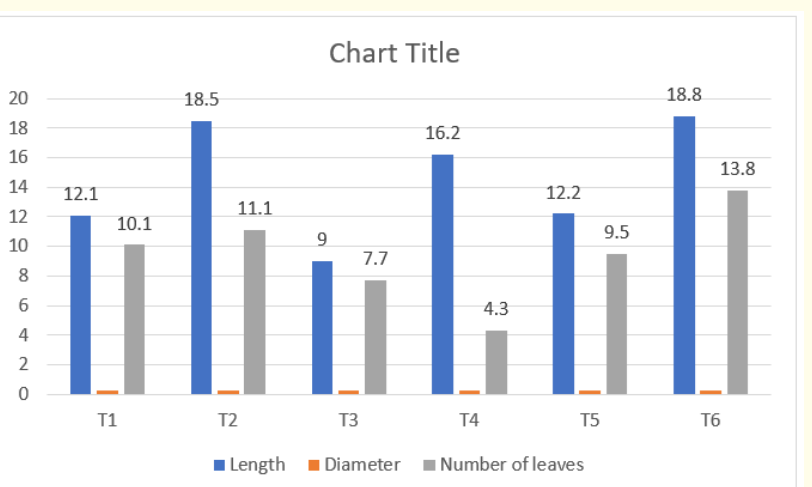

Figure 1: Vegetative growth of Chili plant growth $(\mathrm{cm})$ under nursery condition.

\section{Conclusion}

In this study showed that the combination of Trichocompost and NPK showed the good vegetative growth of chilli plant compare to trichocompost or NKP alone treatments. So it can be concluded that combination of Trichocompost can help to reduce vast using of chemical fertilizer or excessive using $\mathrm{N}$ subsequently it can contribute to minimizing environmental pollution.

\section{Bibliography}

1. Hermosa R., et al. "The contribution of Trichoderma to balancing the costs of plant growth and defence". International Microbiology 16 (2013): 69-80.

2. Ali A and Shaari A. "Mismanagement of Chemical Agriculture in Malaysia from Legal Perspective". Journal of Procedia Economics and Finance 31 (2015): 640650. 
3. Alfred EH. "Soil Fertility Decline: Definitions and Assessment". Encyclopedia of Soil Science (2007): 18-19.

4. Yang W., et al. "Compost addition enhanced hyphal growth and sporulation of arbuscular mycorrhizal fungi without affecting their community composition in the soil". Frontiers in Microbiology 9 (2018): 1-13.

5. Molla AH., et al. "Trichoderma-Enriched Biofertilizer Enhances Production and Nutritional Quality of Tomato (Lycopersicon esculentum Mill.) and Minimizes NPK Fertilizer Use". Agriculture Research 1 (2012): 265-272.

6. Vinale F., et al. "A novel role for Trichoderma secondary metabolites in the interactions with plants". Physiological and Molecular Plant Pathology 72 (2008): 80-86.

\section{Volume 3 Issue 7 July 2019}

(C) All rights are reserved by Laila Naher and Nornadillanadia Binti Abdul Rapar. 